\title{
Future marine zooplankton research - a perspective*
}

\author{
Marine Zooplankton Colloquium 1**
}

Lake Arrowhead Conference Center, Lake Arrowhead, California, USA

18-22 April 1988

\begin{abstract}
Zooplankton research over the past 100 yг has been focused largely on temporal scales of hours to weeks and spatial scales of decameters to kilometers. Research at both greater and lesser scales has been limited mainly by technical intractability. Recent advances in technology are expanding the horizons of enquiry to those scales which have long been difficult to observe. Discussions on future advances in marine zooplankton research and technology from an open meeting of marine zooplanktologists, held at Lake Arrowhead, California, USA in April 1988, led to specific recommendations for future research. Principal issues and areas of future research include: (1) characterization of individual small-scale behaviors leading to a better understanding of the dynamics of aggregation and dispersal; (2) determination of how environmental variability, rather than mean conditions, affects physiology and behavior; (3) relation of birth, death and growth rates to environmental conditions, both concurrent and past; (4) determination of nutritional requirements; (5) long-term observations of population and community dynamics which would permit analysis of interannual variability and its causes; (6) a critical need to maintain expertise in taxonomy; and ( 7 ) continued development of mathematical models encompassing biological, chemical, and physical parameters. Concrete steps that could be taken to facilitate these research goals include: (1) further development of in situ instrumentation that provides (a) measurements at high frequencies and resolutions, (b) the capability for long-term unattended measurements and (c) the ability to monitor birth, growth and physiology; (2) establishment of a Center of Marine Plankton Studies with the full spectrum of facilities required for sophisticated culture, maintenance and experimentation with single or multiple species; and (3) establishment of an Ocean Observatory from which continuous measurements could be made at multiple scales. Significant advances in many areas can be accelerated through multidisciplinary activities.
\end{abstract}

\section{INTRODUCTION}

Marine zooplankton research is currently conducted by individual investigators working largely independently, and with a wide variety of perspectives. To enhance communication, outline significant goals and areas of future study, and to organize future research activity, marine zooplankton researchers recently held a colloquium to discuss their respective views. This meeting followed an open invitation to scientists in the field. As a common organizational frame, 5 ranges of

- This paper is dedicated to Reuben Lasker whose positive attitude and drive inspired many of us

- This paper was authored by the 58 colloquium participants and contributors of abstracts listed at the end of this article, and compiled by G.-A. Paffenhöfer, M. E. Huntley and C. S. Davis. Reprint requests should be directed to G.-A. Paffenhöer, Skidaway Institute of Oceanography, PO Box 13687, Savannah, Georgia 31416, USA time scales were chosen for discussion: seconds to hours, hours to days, days to weeks, weeks to months and months to years. Scientists were asked to submit abstracts about their thoughts on future marine zooplankton research using these time scales as a guide. At the colloquium 5 working groups produced documents on future research goals based on the 5 ranges. Their recommendations and others from the abstracts were edited and are presented in this paper. One realized that success will largely depend on concerted multidisciplinary investigations. An understanding of individual behavior, population dynamics, and community structure and function cannot be obtained without knowledge of physical, chemical and numerous biological processes.

The following thoughts represent primarily the opinion of marine zooplanktologists from the USA. We hope that future colloquia of this kind will allow anyone with interest in our field to participate or contribute with other kinds of input. 


\section{ISSUES AND GOALS}

Many of the problems associated with studying zooplankton have long been recognized. These animals are heterogeneously distributed due to physical and biological processes. They continuously alter locations and behaviors, and can operate at frequencies which cannot be perceived by researchers unaided by technology. It has become obvious that we must (a) strive for observations which are continuous, or at least sufficiently frequent to study the processes in question; (b) conduct these studies wherever possible in situ; and (c) utilize non-invasive/non-disturbing approaches.

To achieve our goals, technology needs to make giant steps forward. One of the major reasons why we were advancing rather slowly during the past decades was that we were not sufficiently ingenious in developing new technology, or applying and modifying that which was available. Advanced technology is required for many reasons, e.g.:

(1) To determine and quantify rapid changes concerning individuals, populations and communities we need sufficiently frequent and adequately spaced observations; these observations may have to be made at frequencies approaching those obtained by physical oceanographers with profilers and current meters. This means we need similar profilers and sufficient numbers of moored instruments, perhaps more than our physical colleagues, to adequately record in situ biological processes. In addition, we need software to rapidly, hopefully instantaneously, process those records.

(2) To monitor effects of our rapidly changing climate (Hansen et al. 1988). Presently our knowledge as to why certain species occur in smaller or larger abundance in certain parts of the ocean is limited (e.g. Colebrook 1985). Climatological changes in the coming decades most likely will alter compositions and abundances of zooplankton. What we need to rapidly and comprehensively assess polar, boreal, subtropical and tropical regions and communities is automated instrumentation with which longer time-series and frequent coverage are possible. Such long-time series could be obtained from an Ocean Observatory (Wiebe et al. 1987). These field studies need to cover processes over scales from seconds to decades, especially to distinguish between natural variance and that created by climatological changes.

\section{Characterization of small-scale individual behavior}

The vast majority of process studies on marine zooplankton in the ocean or in the laboratory have been on populations in assemblages and communities (e.g. Cushing 1963, Petipa et al. 1970, Heron \& Benham
1984). No individual zooplankton organism has been studied over any extended period of time in the ocean. Thus, the distribution and behavior of zooplankton at the level of the individual organism, and their importance to biological and chemical processes in the ocean, are largely unknown. Recently, observational tools such as videomicroscopy and high-speed microcinematography have allowed us to directly observe how zooplankton perceive, respond to, and alter their local environment (e.g. Strickler 1982). These observations have led to the development of mechanistic models of zooplankton processes (e.g. Strickler 1985). It has been argued that variation in population and community patterns can be understood as variation in individual-ecological conditions (Schoener 1986). This implies that observations on individuals can be integrated to understand population and, eventually, community dynamics. Such observations on individuals ideally ought to originate from studies carried out in their natural environment where they encounter all environmental variables. In situ observations on the behavior of individuals should indeed lead to insights not only on population dynamics but on the much more complex issue of community structure (Hassell \& May 1985).

One major focus for field studies in micro-, meso- and macrozooplankton ecology should be to continuously characterize the in situ spatial relationships of organisms. Spatial and temporal heterogeneity of marine zooplankton has been documented only at scales greater than centimeters and minutes (e.g. Bainbridge 1952, Haury et al. 1978). Indirect evidence suggests that distributional heterogeneity also occurs at smaller scales, yet the true microscale environment including micropatch formation and dissipation is at best poorly characterized. We need documentation on scales of milliseconds to minutes and micrometers to centimeters for individual zooplankters which operate on those scales. This goal requires the further development of non-invasive techniques which provide information with submicrometer resolution for bacteria and microzooplankton. In addition, we need to encourage and cooperate with physical oceanographers to increase knowledge on, for example, micro-scale turbulence in situ to understand the distribution and residence time of microscale chemical and physical signals to which zooplankters may respond.

To understand what an individual zooplankter does in its environment and why it may be doing that, we ought to consider the following:

(1) Resource availability relative to the ambit of the zooplankter rather than set by our sampling convenience (Fig. 1). Ambit is defined as the product of perceptive volume (Cushing 1968) and distance traveled for $1 \mathrm{~h}$ or $1 \mathrm{~d}$. Measurements on individual zooplankters 


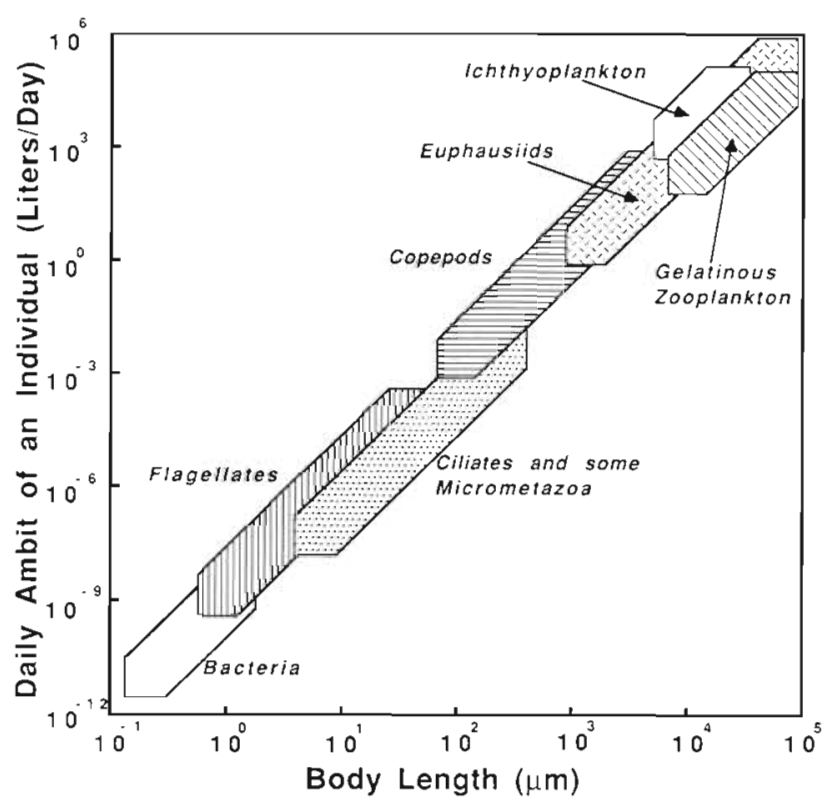

Fig. 1. Generalized relationship between zooplankton body size and volume of water through which the zooplankter might move during its daily ambit. The entire range of body sizes and corresponding ambits for the vast majority of marine heterotrophic plankton is shown, as are the approximate ranges of representative groups

ought to be made on those scales on which they operate. These scales differ markedly for different zooplankton taxa (Fig. 1), ranging over ca 18 orders of magnitude from bacteria to euphausiids.

(2) Random and directed swimming activities of the zooplankter(s) under study, and the effects of physical and also biological (Donaghay et al. 1987, Price et al. 1988a) processes in dispersing and aggregating organisms (see also next section).

(3) Diel patterns in distribution and processes (e.g. feeding, reproduction).

(4) Relative importance of small-scale behaviors to the temporal and spatial distribution of other zooplankton organisms (e.g. predators).

(5) Perceptive volume; this allows a determination of an individual's mechanisms for perception of and response to biological and mechanical stimuli.

(6) Bioenergetics, which includes assimilation, respiration, excretion and defecation by individuals.

\section{Effects of environmental variance on individual physiology and behavior}

Recent work on physical and biological variability in the sea (e.g. Moum et al. 1986, Price et al. 1986, Donaghay 1988) suggests that variance, rather than the average conditions we perceive, may be more important to understanding the response of zooplank- ton organisms, particularly on time scales of hours to days. We suspect that zooplankton process, filter, and integrate part of the variance in their environment through physiological and behavioral mechanisms (Donaghay 1988). The progressive transfer of variance (biological, chemical, physical) from shorter to longer time scales is illustrated in Fig. 2. We suggest that the variance perceived and processed by the individual contributes to its physiological responses and its distribution in the ocean (see also next section). Observations on these behavioral and metabolic activities will be used to develop new models and paradigms not only for individuals and species, but also for populations, communities, and ecosystems. Theoretical and empirical modelling of interactions between individuals and their physical/chemical environment is recommended. Such models are necessary to develop a conceptual framework for these processes (Rothschild \& Osborn 1988) and to aid in synthesis of the large amount of video and acoustical data collected at these scales. In addition, we need to understand variance between individuals (Lomnicki 1988). Individual intraspecific variability occurs, for example, due to age, physiological history or genetic composition.

\section{Growth, fecundity, mortality and predation rates and} their relation to environmental conditions

A change in numbers and biomass due to somatic and reproductive growth, combined with mortality from predation and other causes, are the dominant biological forces driving the population dynamics of species.

Rates of growth and reproduction of zooplankton populations represent an integration of the food environment in which they live. The in situ measurement of growth rates of metazooplankton populations hinges on the ability to (a) sample all stages

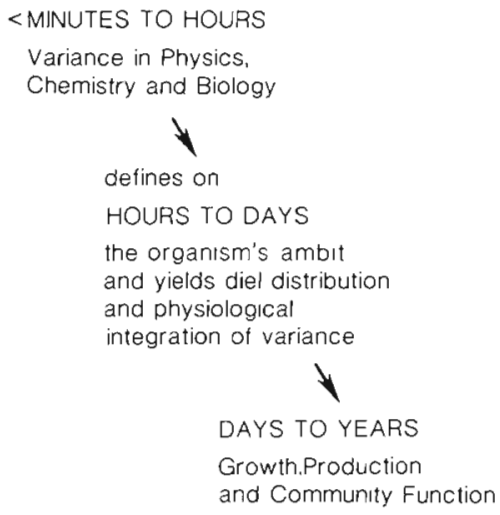

DAYS TO YEARS

Growth,Production and Community Function

Fig. 2. Relevant scales of variance of marine zooplankton 
quantitatively at relevant scales, (b) track the particular population in space over the respective study period, and (c) obtain data on certain biological (e.g. food abundance), chemical and physical variables. This requires physical expertise because e.g. horizontal advection (Lee \& Pietrafesa 1987) and other physical forcings affect the distribution of a zooplankton population with time (e.g. Paffenhöfer et al. 1987). Sampling and observation frequencies need to be tailored to the respective species and the event scales. For example, for species with a generation time of $2 \mathrm{~d}$ (Thalia democratica; Heron \& Benham 1984) a sampling frequency of several hours would be required while for species with generation times of several months (e.g. Neocalanus spp.; Miller et al. 1984) sampling periods of one to several weeks might be needed to determine a population's growth and mortality rate.

Reproductive rates reflect the feeding history of females and integrate small-scale variability. By comparing reproductive rates of females from the ocean with those of females from controlled laboratory experiments, we can compare the extent of food limitation of the field population (Durbin et al. 1983), eventually both quanti- and qualitatively. Laboratory studies are needed to quantify and eventually predict relationships between reproductive rates and food quantity and quality.

To obtain net population growth rates, estimates of mortality rates are needed. A major problem continues to be the accurate and precise determination of mortality of life history stages of zooplankton in the ocean. As with growth rates, a prerequisite of a realistic measurement of mortality requires spatial tracking and proper sampling of the respective zooplankton population over periods ranging from days to weeks. Often the major cause of mortality is predation, which has proven to be difficult to measure in situ. Since the flux of primary production through pelagic ecosystems is influenced by predation, as indicated by simulation models (e.g. Davis 1987), the simultaneous quantification of death and growth rates of prey populations would be needed. In marine systems the concept of predatory control of organism abundance within zooplankton communities and food webs, and their structure and composition, has received little attention. We do not know to what extent predators control the structuring of planktonic marine food webs. Longer-term field studies at the proper spatial and temporal scales, combined with experimental studies, possibly in mesocosms, should be considered for quantifying the abovementioned rates.

Population dynamics can be strongly affected by physical variables, such as advection, turbulence, convergence, diffusion and vertical mixing which occur on various scales. For example, smaller scale differences in the velocity field (vertical and horizontal) of a mesoscale patch can break it into smaller and smaller patches (Mackas et al. 1985). The direct effects of turbulence on zooplankton populations can only be assumed whereas certain advective effects have been studied in the field (e.g. Cox \& Wiebe 1979) and evaluated in theory (e.g. Riley 1976). It is thought that turbulence can affect quality, quantity and size distribution of phytoplankton by e.g. affecting nutrient supply and homogenizing heterogeneous spatial distributions. On small scales, turbulence may affect prey perception of predators and vice versa. Our ignorance of the effects of turbulence requires comprehensive studies on its effect at various spatial scales on zooplankton.

It is important to separate the effects of turbulence from those of advection. One possibility is to study the variability of instantaneous growth and mortality rates of relevant micro- to macrozooplankton populations in a region where turbulence will vary over time, and advection changes little with time and depth.

\section{Definition of nutritional requirements}

Nutritional requirements of zooplankton are almost entirely unknown. Our current information on the nutrition of zooplankton is mostly based on observations of feeding rates and food preferences. However, such empirical experiments yield only circumstantial evidence concerning the specific chemical requirements for growth. Currently, there are no data available which can be used to define what a given zooplankter requires in its diet. Such data are essential to answer long-standing questions regarding 'food quality'. We need data on the food species and quantity eaten in nature, and their biochemical composition and environmental concentration. Laboratory studies should be initiated with the aim of determining the nutritional requirements of several representative taxa and 'life styles' of micro- to macrozooplankton; one approach would be to offer environmentally occurring food species, whereas a second approach would be to precisely control food organism biochemistry. Emphasis should be placed on ontogenetic changes in the dietary requirements of zooplankton to determine to what degree growth of specific stages is regulated by various major organic compounds such as protein, lipid, etc., and specific micronutrients. The results should allow a comparison of the dietary biochemical requirements of a zooplankter with that available in the prey organism(s). These data can be used to predict changes in growth and fecundity of zooplankton in the ocean. 


\section{Long-term population and community dynamics and variability}

In addition to observations of seconds to weeks, we need data over longer periods on zooplankton populations and communities to understand and predict (a) their structure and function, and (b) their long-term variability. So far such studies have been scarce. For example, there are 1 - to 20 -yr high-frequency observations on copepods in the northeast Pacific (Miller et al. 1984) and 35-yr monthly data on zooplankton abundance in the North Sea (Colebrook 1985). The latter showed a dramatic decline in abundance of one copepod species during that period while none of the others increased.

Such long-term studies not only require data on distribution, abundance and composition of zooplankton, but also data on their population dynamics and size structure. Emphasis should be on life history strategies of key species, and comparisons of life history adaptations for species in the same and different regions. Such comparisons should be made within and between phy- sically controlled (e.g. shelves) and biologically controlled regions (e.g. central ocean gyres). Information on life-histories of open ocean zooplankton species is extremely limited. To interpret the biological data various environmental variables, e.g. light, temperature, salinity, atmospheric pressure, wind and current velocities, need to be simultaneously recorded (Robinson \& Hunt 1986). These field observations can be supplemented by short-term experimental studies on key processes such as (a) fecundity of ocean-collected specimens at regular intervals, and (b) organismorganism behavior observations at the long-term study site.

Many of the approaches and data obtained for individuals and populations can probably be used to develop a conceptual framework as to how respective species function within a community. One such framework involves categorizing organisms into functional groups, i.e. groups which characterize how an organism functions within a community or among communities of interest (e.g. feeding guilds). Once such functional groups are established, we can

Table 1. Temporal scales of physical and biological processes, and methods to study the latter

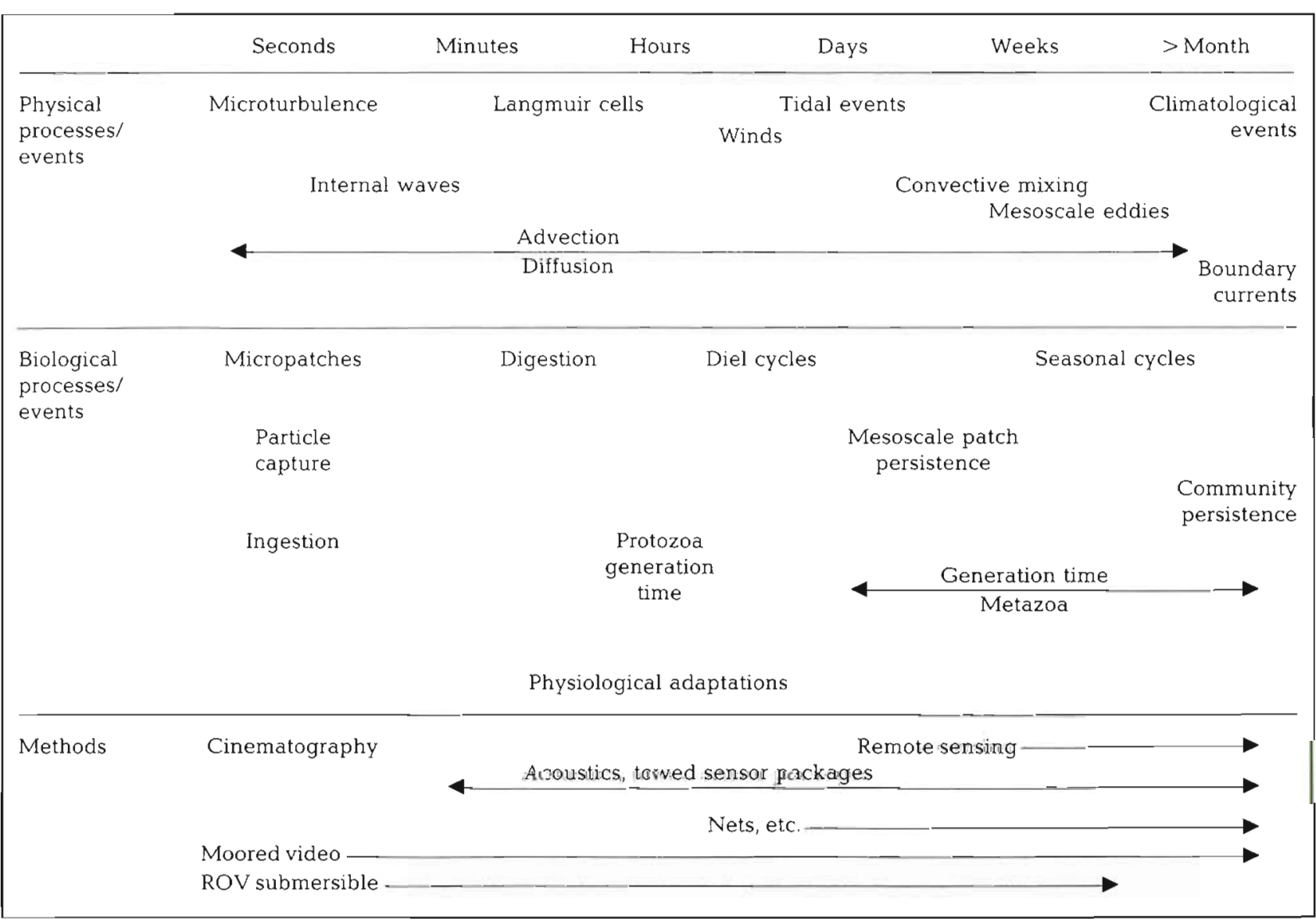


begin to (a) examine patterns of their distribution in space over time, (b) relate these patterns to contemporary and evolutionary environments, and (c) look for co-evolutionary patterns among functional groups.

\section{Significance of species identification}

None of the previously mentioned studies can be conducted without the identification of zooplankton. This is of particular importance not only for adult specimens but also when juvenile stages need to be identified. Particular difficulties arise with identification of nauplii and protozoa. To date the juvenile stages of very few copepod species have been described and can be readily identified. So far the entire suite of juvenile stages has not been taxonomically identified for a single warm-water, open ocean copepod species. Successful studies of population dynamics and community structure studies hinge on the correct identification of all species and stages. The number of competent zooplankton taxonomists has become perilously small, and needs to be increased.

In addition to microscopic identification, we need to develop expertise in identifying zooplankton species in situ.

\section{Biological/physical models}

Since zooplankton are 'drifters', by definition, the question of what controls their distributions is, in part, one of fluid dynamics. To understand these complex interactions, emphasis should be placed on development of coupled individual/physical relations (Rothschild \& Osborn 1988) and also population/physical transport models (e.g. Wroblewski 1982, Hofmann 1988). Both simulation and process oriented models are needed. Information obtained at the individual level should be incorporated into population models.

Combined biological/physical models are also required to understand what regulates zooplankton abundance at the community level. For low diversity areas, multi-species population models of dominants will yield the most accurate insights into community function. For high diversity areas, simplification into size or functional groupings may be the best approach. Assumptions inherent in such groupings need to be rigorously evaluated. Information gleaned from individual population level studies must be incorporated into models of community function. State-of-the-art physical models should be used to generate realistic flow and turbulence fields.

\section{STEPS TO MEETING GOALS}

To address and answer our future objectives we need techniques and technology which allow us to study zooplankton individuals, populations and communities at their appropriate in situ temporal and spatial scales (Table 1).

\section{In situ instrumentation for characterization of small-} scale individual behavior

To be non-invasive, techniques need to be used by which one observes and records zooplankton behavior at certain distances from the recording device $(\mathrm{cm}$ to $>10 \mathrm{~m}$ depending on species). Many of the new techniques at the microscale have been reviewed in an article on questions and technological developments concerning zooplankton behavior (Price et al. 1988b). Studying distribution and behavior of individual zooplankton organisms requires either continuous or very frequent observation in 3 dimensions. The resolution has to be sufficient to identify the zooplankter, possibly its mouthparts, and its food particles and other organisms in its vicinity. For example, a 3-dimensional optical system based on the Schlieren technique has allowed the observation of free-swimming copepods in a 61 vessel with a resolution of $10 \mu \mathrm{m}$ (Strickler 1985) which would be sufficient to resolve many of their food particles. We have to keep in mind that the abovementioned setup allows an observation volume of only about 10 by 10 by $8 \mathrm{~mm}$ at one time. There is a critical need for a system that both greatly expands the observed volume and allows this technology to be used in situ in the ocean. However, we anticipate being able to observe much larger volumes, although with reduced resolution. This would enable us to observe several individuals simultaneously, as well as the interactions between individuals (predator-prey). Another 3-dimensional approach is that of using 2 video cameras mounted parallel to each other so as to provide a stereoscopic image (Hamner et al. 1988). This and other 3-D systems, however, allow identification only of larger organisms such as euphausiids.

In addition to developing techniques to record behavioral response, there is a critical need to develop instruments that can record the stimuli for those behaviors. One example is a high resolution rapid-sampling device under development which allows the identification of phytoplankton characteristics by measuring phytoplankton fluorescence properties at the centimeter scale using laser/fiber optics technology (Cowles et al. 1987). Additional instrumentation is needed to measure dissolved chemical compounds which can affect the behavior of zooplankton (Gill \& Poulet 1988). 
Among other micro-methods are the application of immunological techniques to rapidly examine zooplankton gut contents, and possibly optical flow-visualization by using holography and interferometry to study the distribution of mm-sized eddies which may strongly influence zooplankton behavior.

\section{Techniques and technologies for population and community responses}

The population variables which we want to determine, including rates of birth, growth and mortality and generation time, require tracking of a discrete population in the ocean. In most regions of the world's oceans advection and turbulence vary considerably in space and time (e.g. Price et al. 1986), as do the distribution of biological, chemical and other physical variables. A combination of physical and biological processes will determine whether a zooplankton population persists over an extended period (weeks to $>1 \mathrm{yr}$ ). Persistence should be enhanced in physically stable environments, e.g. shallow and wide continental shelves, as compared with unstable ones, e.g. boundary currents. The type of environment should determine whether the approach is Eulerian, Lagrangian, or both. Development of zooplankton populations is pronounced in mesoscale water masses with nutrient enrichment leading to patch formation (Mackas et al. 1985, Paffenhöfer et al. 1987). Repeated 3-dimensional coverage of the entire patch, coupled with advection data (Paffenhöfer et al. 1987), should provide the desired data on population variables such as birth, growth and mortality rates of species. The frequency of measurements is determined by the rapidity of population processes. Since the direction and velocity of water displacement changes with depth and time, and variability of abundance of a zooplankton species can be greater on smaller than on larger scales (Mackas et al. 1985), coverage of an entire mesoscale patch is preferable to that of part of it, especially when the studies last in excess of several days.

Which methodology could be applied to obtain rapid and repeated coverage of a larger zooplankton patch in 3 dimensions? Acoustic observations on the abundance of various sizes of zooplankton can be made with spatial resolution as small as $1 \mathrm{~m}$ vertically, which could guide the ranges of depth sampling with nets (Pieper et al. 1987). A MOCNESS-type sampler (Wiebe et al. 1976) equipped with various hydrographic sensors would greatly reduce station time and result in quasisynoptic sampling of an entire mesoscale patch. Continuous coverage could be achieved with an optical plankton counter (Herman 1988). The major hurdle would still be zooplankton sample analysis. Unless we are able to obtain continuous biological profiles, using e.g. non-invasive optical recorders covering a volume of about 10 to 1000 l every fraction of a second, we will not be able to cover large areas synoptically and obtain data in real time like physical oceanographers do. These biological profiles would eventually include instantaneous profile analyses of larger zooplankton genera, their size or stages. The software development for such an approach is one of the major obstacles.

We believe, however, that initial steps in this direction can soon be accomplished. Vertical abundance profiles of large, easily identifiable zooplankton species (e.g. doliolids) have recently been made from a submersible using video observations (Youngbluth et al. 1987). Since certain optical systems can be lowered and retrieved quite rapidly, biological profiles of large zooplankters could become common fairly soon. This should result in closer spatial (vertical and horizontal) resolution and more frequent biological coverage of a water mass approaching CTD utilization and immediate (real-time) data analysis. Instead of spending months on microscopic sample analyses, high-resolution profiles of various abundant zooplankton taxa would be available on the same day. Such 3-dimensional, high-frequency sampling with zooplankton size analysis can provide the desired population dynamics variables if we are able to track the respective water mass. This could be facilitated by commercially available on-board acoustic Doppler-profilers which provide instantaneous data on current velocity and direction in relation to depth. In addition, this sampling approach is capable of providing great insight into spatial and temporal variances of distribution and abundance of zooplankton, e.g. formation and dissipation of aggregations. At the same time one ought to obtain data on the 3-dimensional distribution and abundance of potential food particles (Cowles et al. 1987, Price et al. 1988b). Such sensors (resolution of $<10 \mu \mathrm{m}$ ) would provide information about particle size distribution and type (diatom, protozoan, dinoflagellate, living or dead).

\section{Center for Marine Plankton Studies}

As we expressed earlier, we will not immediately have the technology to conduct all the suggested studies of individuals, populations and communities in situ within the next few years. We therefore recommend establishing a Center of Marine Plankton Studies. In such a Center investigators would be able to simulate environmental conditions in large bodies of water in a sophisticated manner. This simulation of the environment would allow study of species interactions by remote observation and to gain insight into proces- 
ses which are otherwise extremely difficult to observe in situ at present levels of technology such as determining nutritional requirements, mortality, growth and reproduction rates. Such a Center would also permit studies of community interactions which are difficult to observe in the ocean. It could develop into an international and multidisciplinary Center of Marine Plankton Studies covering experimentation from sensory physiological processes on the submicron and subsecond scales to those involving zooplankton patch or swarm formation where persistence and dissipation occur on scales of days and tens of meters. It could also include approaches to examine the effects of turbulence on communities as well as individuals over extended periods of time (Alcaraz et al. in press). Other advantages include the ability to conduct detailed bioenergetic studies, to establish a zooplankton culture collection and to study population behavior.

\section{Ocean Observatory}

Long-term studies in the ocean have been run at intervals of months or more using ships. To obtain data frequently over years in the oceanic environment we need stable platforms which can serve as Ocean Observatories (Wiebe et al. 1987). Continuous unattended measurements on any variable relevant to marine zooplankton can be obtained on or from such an observatory. In addition, experiments on individuals, populations and community dynamics can be carried out at any time because zooplankton can be collected around the clock, depending on weather. Such a stable platform could house numerous scientists simultaneously.

\section{Submersibles}

To study in situ, at depths of $>30 \mathrm{~m}$, the behavior of individual zooplankton, patches and swarms, we require manned submersibles and/or remotely operated vehicles. Especially the latter could be applied when rapid vertical high-resolution profiles are needed, and could also be used to study horizontal patchiness.

\section{Zooplankton identification}

First of all, we need to broaden our knowledge in the identification of all stages and life forms of marine zooplankton by describing all stages of oceanic species. Second, we need to increase the number of taxonomists. Third, we need to develop taxonomic identification in situ. The major difficulty seems to be taxonomic identification of, e.g. recorded 3-dimensional profiles. To identify various species in situ we need sufficient resolution for shape analysis, and a sufficient volume for movement analysis. A combination of morphological and behavioral components appears to be necessary for taxonomic identification. The resolution ought to be less than $1 \mu \mathrm{m}$ for micro-, and about $50 \mu \mathrm{m}$ for macrozooplankton. Software development for this taxonomic analysis will require a major effort. Immunological tags could eventually prove useful in the identification of species.

The initial investment for technological development, and the one-time expenditures for equipment, may be high. It may, however, be low (consider the analog of a CTD) when the tremendous gain in insight and understanding of functioning of oceanic communities and ecosystems is considered.

\section{Biological/physical model development}

Continued model development is needed at almost every temporal and spatial scale of zooplankton including small scales. To test and improve these models we need certain empirical data. Foremost on the population level are in situ zooplankton mortality rates because this is the variable to which population models are most sensitive (Hofmann 1988). We also need realistic flow field data as input among physical variables. Not only super computers but also VAX-type computers should be considered as capable of modeling biological/physical interactions.

\section{SUMMARY OF MAJOR RECOMMENDATIONS}

(1) Study the interaction of individuals and aggregations of zooplankton with their patchy abiotic and biotic environment on environmentally relevant scales of micrometers to kilometers and milliseconds to years.

(2) Regard/perceive zooplankton as living in a continuum of processes; studies should consider their responses to variance - not to the mean - of biological, chemical and physical parameters on multiple time and space scales.

(3) Obtain in situ rates on birth, mortality and growth of zooplankton populations, including prey and predator populations; in particular, quantification of mortality rates of all life history stages of relevant zooplankton species is required.

(4) Determine nutritional requirements of representative zooplankton taxa and 'life styles'.

(5) Establish long-term data acquisition of environmental ocean variables, in particular on zooplankton abundance and community structure. 
(6) Determine in situ rates of zooplankton mortality with particular reference to predatory control of abundance, structure, and composition of marine planktonic food webs.

(7) Determine the effects of seasonal temperature changes, turbulence and advection on zooplankton, their food and predators.

(8) Develop new and improve existing technology to enable us to obtain in situ information on individuals, populations and communities continuously or at environmentally relevant frequencies in 3 dimensions.

(9) Establish (a) a Center for Marine Plankton for experimental studies on marine zooplankton; (b) Ocean Observatories for long-term (decade) data acquisition of ocean and atmospheric variables to understand and predict interannual changes in zooplankton abundance and community structure; and (c) regular availability of manned submersibles and remotely operated vehicles for in situ observations at greater depths.

(10) Improve expertise on species identification of preserved zooplankton, and develop technology to identify living zooplankton in situ.

(11) Develop biological-physical models to quantify/ predict (a) turbulence on the millimeter scale and the responses of individual zooplankters to it, and (b) how populations and communities are affected by various physical processes on small and large scales in the ocean.

Acknowledgements. Special thanks are due to Drs Edward Frieman, Robert Gagosian, David Menzel, and John Steele (alphabetical order) whose personal commitments of unconditional institutional support made it possible to increase attendance at the Lake Arrowhead meeting. Participants agreed that Cabell Davis, Mark Huntley and Gustav-Adolf Paffenhöfer (alphabetical order) should be recognized for their joint efforts in organization of the meeting and initial preparation of this manuscript. Post-meeting contributions by numerous participants were in the spirit of the meeting by following through with constructive contributions. The greatest acclaim, however, is due to all scientists who participated in the Lake Arrowhead meeting, by submitting written abstracts and attending the $4 \mathrm{~d}$ conference. Most of those who attended (listed below) made sacrifices of time or money in order to do so. It is only because of such broad participation that the ideas presented in this paper can claim to be representative of the field of marine zooplankton research as a whole.

Colloquium Participants: T Ayukai, E. Brinton, A. C. Bucklin, D. A. Caron, M. E. Clarke, T J. Cowles, C. S. Davis, P. L. Donaghay, D. J. Gifford, C. H. Greene, J. Hakanson, R. P. Harris, L. R. Haury, E. E. Hofmann, M. E. Huntley, T Kiørboe, G. S. Kleppel, P. Kremer, D. T. Manahan, P. Mayzaud, J. McGowan, M. M. Mullin, M. D. Ohman, G.-A. Paffenhofer, R. E. Pieper, S. A. Poulet, H. J. Price, F. Rassoulzadegan, S. Razouls, K. Richter, R. S. Scheltema, B. F. Sherr, E. H. Sherr, S. L. Smith, D. K. Stoecker, J. R. Strickler, J. J. Torres, J. T. Turner, S. Uye, H. A. Vanderploeg, P. G. Verity, P. H. Wiebe, R. Williams.
Scientists who contributed with abstracts: J. W Ambler, R. J. Conover, D. Deibel, A. G. Durbin, S. G. Ellis, S. M. Gallager, T L. Hopkins, R. Lasker, E. Lessard, I. A. McLaren, C. B. Miller, C. Razouls, L. F. Small, D. E. Stearns, M. J. Youngbluth.

\section{LITERATURE CITED}

Alcaraz, M., Estrada, M., Marrase, C. (1988). Interaction between turbulence and zooplankton in laboratory microcosms. In: Proceedings of the 21st European Marine Biology Symposium, Gdansk, Poland (in press)

Bainbridge, R. (1952). Underwater observations on the swimming of marine zooplankton. J. mar. biol. Ass. U.K. 31. $107-112$

Colebrook, J. M. (1985). Continuous plankton records: overwintering and annual fluctuations in the abundance of zooplankton. Mar. Biol. 84: 261-265

Cowles, T. J., Moum, J. N., Desiderio, R. A. (1987). Rapid, high resolution profiling of algal fluorescence using laser/fiber optics. EOS 68: 1683

Cox, J., Wiebe, P. H. (1979). Origin of oceanic plankton in the middle Atlantic Bight. Estuar. coast. Shelf Sci. 9: 509-527

Cushing, D. H. (1963). Studies on a Calanus patch. V The production cruises in 1954: summary and conclusions. J. mar biol. Ass. U.K. 43: 387-389

Cushing, D. H. (1968). Grazing by herbivorous copepods in the sea. J. Cons. perm. int. Explor. Mer 32: 70-82

Davis, C. B. (1987). Components of the zooplankton production cycle in the temperate ocean. J. mar. Res. 45: 947-983

Donaghay, P. L. (1988). Role of temporal scales of acclimation, food quality and trophic dominance in controlling the evolution of copepod feeding behavior Bull. mar. Sci. 43: $469-485$

Donaghay, P. L., Rines, H., Campbell, R., French, D. (1987). The relative importance of physical-biological interactions in controlling plankton patch dispersal: an experimental ecosystem study. EOS 68: 1739

Durbin, E. G., Durbin, A. G., Smayda, T J., Verity, P. G. (1983). Food limitation of production by adult Acartia tonsa in Narragansett Bay, Rhode Island. Limnol. Oceanogr 28: $1199-1213$

Gill, C. W., Poulet, S. A. (1988). Responses of copepods to dissolved free amino acids. Mar. Ecol. Prog. Ser 43: 269-276

Hamner, W M., Prewitt, C. T., Kristof, E. (1988). Quantitative analyses of the abundance, swimming behavior and interactions of midwater organisms. NOAA Symp. Series for Undersea Res. 6 (in press)

Hansen, J., Fung, I., Lacis, A., Rind, D., Lebedeff, S., Ruedy, R., Russell, G. (1988). Global climate changes as forecast by Goddard Institute for Space Studies three-dimensional model. J. geophys. Res. 93: 9341-9364

Hassell, M. P., May, R. M. (1985). From individual behavior to population dynamics. In: Sibly, R. M., Smith, R. H. (eds.) Behavioral ecology: ecological consequences of adaptive behavior. Blackwell Scientific, Oxford, p. 3-32

Haury, L. R., McGowan, J. A., Wiebe, P. H. (1978). Patterns and processes in the time-space scales of plankton distributions. In: Steele, J. H. (ed.) Spatial patterns in plankton communities. NATO Conferences Series. Series IV: Marine Sciences. Plenum Press, New York, p. 277-327

Herman, A. W. (1988). Simultaneous measurement of zooplankton and light attenuance with a new optical plankton counter. Cont. Shelf Res. 8: 205-221

Heron, A. C., Benham, E. E. (1984). Individual growth rates for salps in three populations. J. Plankton Res. 6: 811-828 
Hofmann, E. E. (1988). Plankton dynamics on the outer southeastern U.S. continental shelf. III. A coupled physicalbiological model. J. mar Res. 46: 919-946

Lee, T N., Pietrafesa, L. J. (1987). Summer upwelling in the southeastern continental shelf of the U.S.A. during 1981. circulation. Prog. Oceanogr. 19: 267-312

Lomnicki, A. (1988). Population ecology of individuals. Princeton University Press, Princeton

Mackas, D. L., Denman, K. L., Abbott, M. R. (1985). Plankton patchiness: biology in the physical vernacular. Bull. mar. Sci. 37: 652-674

Miller, C. B., Frost, B. W., Batchelder, H. P., Clemons, M. J. Conway, R. E. (1984). Life histories of large, grazing copepods in a subarctic ocean gyre: Neocalanus plumchrus, Neocalanus cristatus and Eucalanus bungii in the northeast Pacific. Prog. Oceanogr. 13: 201-243

Moum, J. N., Caldwell, D. R., Paulson, C. A., Chereskin, T K (1986). Does ocean turbulence peak at the equator? J. phys. Oceanogr. 16: 1991-1994

Paffenhöfer, G.-A., Sherman, B. K., Lee, T N. (1987). Summer upwelling on the southeastern continental shelf of the U.S.A during 1981. abundance, distribution and patch formation of zooplankton. Prog. Oceanogr. 19: 403-436

Petipa, T. S., Pavlova, E. V., Mironov, G. N. (1970). The food web structure, utilization and transport of energy by trophic levels in the planktonic communities. In: Steele, J. H. (ed.) Marine food chains. Oliver and Boyd, Edinburgh, p. $142-167$

Pieper, R. E., Holliday, D. V., Kleppel, G. S. (1987). Dynamics of small scale spatial distributions of zooplankton. EOS 68: 1724

Price, H. J., Boyd, K. R., Boyd, C. M. (1988a). Omnivorous feeding behavior of the Antarctic krill Euphausia superba. Mar. Biol. 97: 67-77

Price, H. J., Paffenhöfer, G.-A., Boyd, C. M., Cowles, T. J., Donaghay, P. L.. Hamner, W M., Lampert, W., Quetin, L. B., Ross, R. M., Strickler, J. R., Youngbluth, M. J. (1988b).

This article was submitted to the editor
Future studies of zooplankton behavior: questions and technological developments. Bull. mar. Sci. 43: 853-872

Price, J. A., Weller, R. A., Pinkel, R. (1986). Diurnal cycling: observations and models of the upper ocean response to diurnal heating, cooling, and wind-mixing. J. geophys. Res. 91: 8411-8427

Riley, G. A. (1976). A model of plankton patchiness. Limnol. Oceanogr. 21: 873-880

Robinson, G. A., Hunt, H. G. (1986). Continuous plankton records: annual fluctuations of the plankton in the western English Channel, 1958-83. J. mar. biol. Ass. U.K. 66: 791-802

Rothschild, B. J., Osborn, T R. (1988). Small-scale turbulence and plankton contact rates. J. Plankton Res. 10: 465-474

Schoener, $\Upsilon$. W. (1986). Mechanistic approaches to community ecology: a new reductionism? Am. Zool. 26: 81-106

Strickler, J. R. (1982). Calanoid copepods, feeding currents and the role of gravity. Science 218: 158-160

Strickler, J. R. (1985). Feeding currents in calanoid copepods: two new hypotheses. In: Laverack, M. S. (ed.) Symposia of the Society of Experimental Biology, No. 39; Physiol. Adapt. of Marine Animals. The Company of Biologists Limited, Cambridge, p. 459-485

Wiebe, P. H., Burt, K. H., Boyd, S. H., Morton, A. W. (1976). A multiple opening/closing net and environmental sensing system for sampling zooplankton. J. mar. Res. 34: 313-326

Wiebe, P. H., Miller, C. B., McGowan, J. A., Knox, R. A. (1987). Long time series study of oceanic ecosystems. EOS 68: $1178,1180-1183,1185,1187-1190$

Wroblewski, J. S. (1982). Interaction of currents and vertical migration in maintaining Calanus marshallae in the Oregon upwelling zone - a simulation. Deep Sea Res. 29 665-686

Youngbluth, M. J., Paffenhöfer, G.-A., Bailey, T G., Davoll, P. J. (1987). Massive bloom of the colonial, gelatinous diatom Thalassiosira subtilis in upwelled waters: distribution, abundance, productivity and fate: a submersible study EOS 68: 1724

Manuscript first received: December 22, 1988

Revised version accepted: April 26, 1989 